\title{
Ms. No.: NSC-12-1582: Periadolescent ethanol vapor exposure persistently reduces measures of hippocampal neurogenesis that are associated with behavioral outcomes in adulthood
}

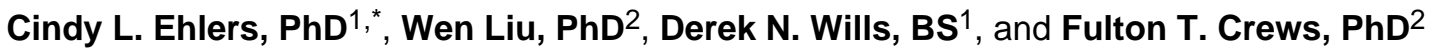 \\ ${ }^{1}$ Department of Molecular and Cellular Neurosciences, The Scripps Research Institute, 10550 \\ North Torrey Pines Road, La Jolla, CA 92037, USA \\ ${ }^{2}$ Bowles Center for Alcohol Studies University of North Carolina at Chapel Hill, Chapel Hill, North \\ Carolina, USA
}

\section{Abstract}

\begin{abstract}
Excessive alcohol consumption is prevalent among adolescents and may result in lasting neurobehavioral consequences. The use of animal models to study adolescent alcohol exposure has the advantage of allowing for the control necessary in order to evaluate the effects of ethanol on the brain and separate such effects from genetic background and other environmental insults. In the present study the effects of moderate ethanol vapor exposure, during adolescence, on measures of neurogenesis and behavioral measures were evaluated at two different times following ethanol withdrawal, in adulthood. The two groups of Wistar rats were both exposed to intermittent ethanol vapor (14 hrs on/10 hrs off/day) for 35-36 days from PD 23-PD 58 (average blood ethanol concentration (BEC): $163 \mathrm{mg} \%$ ). In the first group, after rats were withdrawal from vapor they were subsequently assessed for locomotor activity, conflict behavior in the open field, and behaviors in the forced swim test and then sacrificed at 72 days of age. The second group of rats were withdrawn from vapor and injected for 5 days with Bromo-deoxy-Uridine (BrdU). Over the next 8 weeks they were also assessed for locomotor activity, conflict behavior in the open field, and behaviors in the forced swim test and then sacrificed at 113/114 days of age. All rats were perfused for histochemical analyses. Ethanol vapor exposed rats displayed hypoactivity in tests of locomotion and less anxiety-like and/or more "disinhibitory" behavior in the open field conflict. Quantitative analyses of immunoreactivity revealed a significant reduction in measures of neurogenesis, progenitor proliferation, as indexed by doublecortin (DCX), Ki67, and increased markers of cell death as indexed by cleaved caspase-3, and Fluoro-Jade at 72 days, and decreases in doublecortin (DCX), and increases in cleaved caspase-3 at 114 days in the ethanol vapor exposed rats. Progenitor survival, as assessed by BrdU+, was reduced in the vapor exposed animals that were sacrificed at 114 days. The reduction seen in DCX labeled in cell counts was significantly correlated with hypoactivity at 24 hours after withdrawal as well as less anxiety-like and/or more "disinhibitory" behavior in the open field conflict test at 2 and 8 weeks following termination of vapor exposure. These studies demonstrate that behavioral measures of disinhibitory behavior correlated with decreases in neurogenesis are all significantly and persistently impacted by periadolescent ethanol exposure and withdrawal in Wistar rats.
\end{abstract}

(C) 2013 IBRO. Published by Elsevier Ltd. All rights reserved.

*Corresponding author. Molecular and Cellular Neurosciences Department, The Scripps Research Institute, 10550 North Torrey Pines Road, SP30-1501, La Jolla, CA 92037, USA. Tel.: +1 858784 7058; fax: +1 858784 7409; cindye@ scripps.edu (C.L.Ehlers).

Publisher's Disclaimer: This is a PDF file of an unedited manuscript that has been accepted for publication. As a service to our customers we are providing this early version of the manuscript. The manuscript will undergo copyediting, typesetting, and review of the resulting proof before it is published in its final citable form. Please note that during the production process errors may be discovered which could affect the content, and all legal disclaimers that apply to the journal pertain. 


\section{Keywords}

Adolescent; alcohol exposure; neurogenesis; forced swim test; open field conflict; startle

\subsection{INTRODUCTION}

Adolescence is a period of cognitive, emotional, and social maturation suggested to encompass the entire second decade of life in humans (10-20 yrs) (Spear, 2000; Dahl and Spear, 2004). In addition to the onset of puberty, adolescence is also a critical stage of brain development associated with changes in synapse numbers (Huttenlocher, 1984). During adolescence, there are also major changes that occur in brain morphology including the selective removal of 40 to $50 \%$ of the synapses (i.e., synaptic pruning) in cortical and subcortical brain regions (van Eden, 1990; Lidow et al., 1991; Johnston, 1995; Seeman, 1999), continued myelination of cortical regions (Giedd et al., 1996; Sowell et al., 1999b), and dramatic changes in receptor levels and sensitivity (Gould et al., 1991; Lidow et al., 1991). Adolescence is also a time when humans are initially exposed to a number of potentially toxic external stimuli such as ethanol and other drugs of abuse (Johnston, 1995; Clark et al., 2008; Squeglia et al., 2009). Given that the brain continues to develop before and throughout the adolescent period into early adulthood (Markus and Petit, 1987; Pfefferbaum et al., 1994; Sowell et al., 1999a, 1999b), ethanol and other drug exposure during that time period may have unique deleterious consequences including changes in brain morphology.

In spite of these well-documented changes in brain structure and function, compared with the study of fetal ethanol effects, fewer studies have assessed the long-term effects of chronic drug or ethanol exposure on adolescent brain or behavior during this crucial time of development (Trauth et al., 2000; White et al., 2000; Dahl and Spear, 2004). It is known that the adolescent brain is highly sensitive to excitotoxic insult, particularly in cortical and hippocampal regions (Johnston, 1995). Several MRI studies of adolescent alcohol users have found hippocampal volume decreases associated with their alcohol use (see DeBellis et al., 2000; Nagel et al., 2005; Medina et al., 2007). However, studies in human adolescent studies cannot distinguish whether hippocampal volume decreases represent a consequence of alcohol use or exposure to other adverse environmental conditions (Staff et al., 2012), or are a pre-existing condition associated with risk for alcohol use. However, recently, reductions in the volume of the hippocampus were detected in MRI studies in rats exposed to ethanol vapor during adolescence and subsequently evaluated as adults (Ehlers et al., 2013). Although the mechanisms that result in this reduction in adult hippocampal volume following periadolescent ethanol exposure remain unknown, these findings suggest that adolescent ethanol exposure can impact adult hippocampal structure.

The hippocampus represents a unique brain structure in that it is one of two brain regions where neurogenesis extends into adulthood (see Zhao et al., 2008). Neurogenesis emerges from a population of neural progenitor cells (NPC) that exist in the forebrain subventricular zone (SVZ) and in the hippocampal dentate gyrus (DG) (Altman and Das, 1965, Doetsch et al., 1999). The formation of new neurons progresses over 3-6 weeks through a set of stages that include: NPC proliferation, cell migration, neuronal differentiation and survival of new neurons or neuronal death. It is thought that a number of the components of hippocampal neurogenesis may be impacted by stress (Barha et al., 2011), inflammation (Whitney et al., 2009), and chronic sleep restriction (Novati et al., 2011) that may also potentially result in reduced hippocampal volume. Neural stem cells of the hippocampus have been linked to a number of functions of the hippocampus including, memory, learning, depression and anxiety (see Balu and Lucki, 2009; Hanson et al., 2011). Adolescent rats have been shown to 
have higher levels of hippocampal neurogenesis than adults, with measures of neurogenesis decreasing during brain maturation from adolescence to adulthood (He and Crews, 2007). Reduced hippocampal volume and lower levels of hippocampal neurogenesis have been suggested to underlie the symptomatology and etiology of emotional and depressive disorders that typically arise during adolescence (see Sapolsky, 2000; Czeh and Lucassen, 2007; Perera et al., 2008; Boldrini et al., 2009). There is also a growing body of data to suggest that neurogenesis during adolescence is potently impacted by alcohol exposure during that time period.

The effects of adolescent ethanol exposure on neurogenesis in the rat hippocampus have only been studied by a few investigators using primarily short-term (1-4 days) ethanol exposure paradigms. These studies have found that adolescents are more sensitive than adults to ethanol-induced inhibition of brain neurogenesis (Crews et al., 2006). Acute oral administration (by gavage) of doses of ethanol $(1.0,2.5,5.0 \mathrm{~g} / \mathrm{kg}$ ), that mimic "binge drinking", often seen during adolescence, have been demonstrated to dose dependently inhibit NPC proliferation in both forebrain and hippocampus (Crews et al., 2006). Multi-day exposure to "binge-like" levels of blood alcohol during adolescence has additionally been shown to result in both reduced cell proliferation and impaired survival as well as increases in several cell death markers in the dentate gyrus (Morris et al., 2010). Adolescent binge alcohol may also accelerate progression through the cell cycle (McClain et al., 2011). It appears that most of the cells that do survive this treatment become neurons and that newborn cells differentiate into neurons in a slighter higher rate in adolescents than adults (He et al., 2005, Morris et al., 2010). Hippocampal neurogenesis has also been evaluated in primate brain following "heavy drinking" over an 11 month period during adolescence. In that study alcohol associated reductions in the division and migration of hippocampal preneuronal progenitors were found (see Taffe et al., 2010). Although these studies demonstrate clear evidence of alcohol induced interference with adolescent neurogenesis, it is not known whether these findings are associated with behavioral pathology in the alcohol exposed animals nor is it known how long lasting the effects are.

The present investigation was designed to extend previous studies in adolescent rats in order to study the effects of moderate levels of chronic ethanol vapor exposure during adolescence and early adulthood on behaviors and measures of neurogenesis in adulthood at 2 weeks and 8 weeks following withdrawal from ethanol vapor exposure. The measures of neurogenesis used in the study were: Ki-67 labeling, an endogenous cell cycle protein expressed in actively dividing cells from G1-phase through M-phase (Scholzen and Gerdes, 2000), and Doublecortin (DCX) a marker of immature neurons at both time points (71/72 (collectively referred to as 72) and 113/114 (collectively referred to as 114) days, 2 and 8 weeks following withdrawal), as well as Bromo-deoxy-Uridine (BrdU), a thymidine analog that is incorporated into cells in place of a thymine base pair as the cell undergoes DNA replication during the $\mathrm{S}$ phase of the mitotic cell cycle, and as such is a measure of cell proliferation at the second time point (114 days, 8 weeks following withdrawal). Cleaved caspase-3+IR, a marker of cell death, was also measured at 72 and 114 days. The behaviors in both groups (72 and 114 days) included: locomotion, behavior in the modified open field, and immobility and defecation in the forced swim test. The results of the body weights, blood ethanol concentrations, behaviors, diffusion tensor imaging and choline acetyl transferace immunoreactivity in a larger group of animals that included some of those in the present study, who were sacrificed at 72 days, has been reported previously (Ehlers et al., 2011, 2013). 


\subsection{EXPERIMENTAL PROCEDURES}

\subsection{Subjects}

Male Wistar rats and their dams who were received at postnatal day (PD) $21(\mathrm{n}=42)$, Charles River, USA) were used in this study. The adolescent animals (PD 21) were housed 3 per cage respectively, in standard cages, until PD70 (for study 2 only) when they were housed 2 per cage for the duration of the experiment. Animals were kept in a light/dark (12 hrs light/12 hrs dark) and temperature-controlled environment. Food and water were available ad libitum throughout the experiment. All experimental protocols were approved by the Institutional Animal Care and Use Committee at The Scripps Research Institute and were consistent with the guidelines of the NIH Guide for the Care and Use of Laboratory Animals (NIH Publication No. 80-23, revised 1996).

\subsection{Ethanol vapor exposure and BrdU administration}

Ethanol vapor exposure has been shown to reliably allow for the titration of blood ethanol concentrations (BECs) that are sufficient for inducing ethanol physical dependence (see Roberts et al., 1996, 2000). The ethanol vapor inhalation procedure and the cages used in this study have been previously described (Rogers et al., 1979; Slawecki et al., 2001; Slawecki, 2002; O’Dell et al., 2004; Funk et al., 2006; Gilpin et al., 2008; Ehlers et al., 2011, 2013; Zahr et al., 2011). Ethanol vapor exposure was calibrated to produce high to moderate BECs between 150-225 mg/dL. In brief, adolescent animals were randomly divided into two ethanol and control groups: group 1 sacrificed at 71 or 72 (collectively referred to as 72) days of age: ethanol-exposed group $(n=12)$, control group $(n=7)$; group 2 sacrificed at 113 or 114 (collectively referred to as 114) days of age: ethanol-exposed group $(n=13)$, control group $(n=10)$. Ethanol-exposed rats were housed in sealed cages, which were infused with vaporized $95 \%$ ethanol beginning at lights off for $14 \mathrm{hrs}$. For the remaining of the $10 \mathrm{hrs}$ of the day, ethanol vapor was not infused into the cages. Control rats were in similar cages but were exposed to ambient air, and were handled identically to ethanol-exposed rats. At the start of the ethanol exposure, adolescent rats were 23 days old and the exposures continued until they were 57-58 days old. Food and water were always available. Blood samples were collected from the tip of the tail approximately 8 times during the 5 week exposure period in order to assess BECs (target: 150 to $200 \mathrm{mg} / \mathrm{dl}$ ). Control animals also had blood removed from the tail at the same time points. BECs were determined in the ethanol exposed animals using the Analox micro-statGM7 (Analox Instr. Ltd., Lunenberg, MA). Following the 5 week exposure animals were tranferred to standard vivarium cages for the duration of the experiments. Body weights and BECs in the first group of animals has been previously published (Ehlers et al., 2011).

The second group of animals was injected with BrdU, 72 hours following final withdrawal from ethanol, once a day for 5 days between PD61 and PD65. The dose of BrdU was 150 $\mathrm{mg} / \mathrm{kg}$, it was disolved in $0.007 \mathrm{~N} \mathrm{NaOH}$ and $0.9 \%$ saline and it was given between 11:00 and 13:00 hours each of the 5 days.

\subsection{Locomotor activity}

Locomotor activity has been demonstrated to be a sensitive measure of ethanol vapor exposure levels and withdrawal (Ehlers and Chaplin, 1987; Slawecki et al., 2005; Ehlers et al., 2011). Locomotor activity was measured at PD58/59, $24 \mathrm{hrs}$ following withdrawal of ethanol vapor, in both experimental groups, and additionally at 5 weeks following withdrawal in the second group of animals. Locomotion was measured in individual wire cages $(20 \mathrm{~cm} \times 25 \mathrm{~cm} \times 36 \mathrm{~cm})$. Each cage was equipped with two infrared photocell beams placed $2 \mathrm{~cm}$ above the floor. Activity was initially quantified by totaling photocell beam interruptions which were recorded on electromechanical counters for 5 minute epochs over 
the entire test session. The results of the locomotor measures in the first group have been previously published (Ehlers et al., 2011).

\subsection{Modified open field conflict}

Assessment of anxiety-like behavior/ disinhibition was accomplished in the modified open field at PD105/106, 46 days after final withdrawal from ethanol vapor. This procedure has been demonstrated previously in our lab to be highly sensitive to periadolescent drug exposure (Slawecki et al., 2003). The description of the test apparatus, in the first group, as well as the results of vapor exposure on their behavior has been previously published (Ehlers et al., 2011). The test apparatus in the second group was constructed from a standard square 9 quadrant open field of dimensions $117 \mathrm{~cm} \times 117 \mathrm{~cm} \times 46 \mathrm{~cm}$ high. The center quadrant was illuminated by a single white spotlight (100 lux) located $3.5-4$ feet above the floor of the apparatus. A single $5 \mathrm{~g}$ food pellet coated with peanut butter was fixed in place at the center of the apparatus prior to each test. Twenty-four hours prior to the test, all subjects were food deprived. To start each test, a rat was placed facing away from the center of the apparatus. Since the animals have been food deprived they would be motivated to approach and eat the food pellet, however, the presence of a bright light shining on the food pellet will also produce a reluctance to approach the food, thus producing a behavioral conflict situation. Increased contact with the food by treated rats suggests disinihibited behavior and/ or less "anxiety-like" behavior as compared to controls. Rats were given 5 minutes to freely explore the apparatus. Time spent in the center of the open field, mean distance from the food pellet, time spent in contact with the food, and the amount of food eaten were recorded during each test. At the conclusion of the test, the rat was returned to its home cage. The apparatus was cleaned with vinegar and water prior to assessing the next subject. Tests were run between 9 a.m. and 3 p.m. On the test day, individual ethanol and control rats were run in an alternating fashion. An individual, who was blind to treatment group, scored behavior in the modified open field (Slawecki et al., 2003).

\subsection{Forced swim test}

Immobility in the forced swim test (FST) has been demonstrated to be enhanced in animals that experience periadolescent alcohol vapor exposure (Slawecki et al., 2004) as well as adults exposed to ethanol vapors (Walker et al., 2010). Animals were tested in the force swim test in the first group rats at PD69/70, 12-13 days following termination of ethanol exposure and the results have been reported previously (Ehlers et al., 2011). The second group of rats was tested at PD111/112, 53-54 days following termination of ethanol exposure. In both cases the FST apparatus was a white plastic tub (diameter $=34 \mathrm{~cm}$, height $=66 \mathrm{~cm}$ ). The tub was filled to a level of $48 \mathrm{~cm}$ with $24 \pm 2^{\circ} \mathrm{C}$ water. Illumination at the surface of the water was approximately 60 lux. The first day of the test rats were placed in the apparatus for 10 minutes but behavior was not recorded. On the second day of the test, behavior in the apparatus was assessed during a 5 minute test session. Each test session was videotaped and later analyzed by two researchers that were blind to the exposure conditions. The behaviors that were measured in the 5 minute FST consisted of latency to immobility after being placed in the apparatus, swim time, immobility time and defecation. Immobility time was defined as a lack of active swimming and floating/ and or sinking. Inter-rater reliability was very high, with less than $10 \%$ deviation between scorers on all parameters that were evaluated.

\subsection{Perfusion, brain preparation and immunohistochemistry}

Rats were sacrificed after two different elapsed time periods following withdrawal from ethanol vapor. In the first group, rats were sacrificed on postnatal days 71-72, 2 weeks following withdrawal and in the second group the rats were sacrificed on postnatal days $113-114,8$ weeks after the termination of vapor exposure. They were first anesthetized with 
pentobarbital (100 mg/kg, intraperitoneal) and then killed by perfusion as described previously (Crews et al., 2004). The animals were perfused transcardially with $0.1 \mathrm{M}$ phosphate buffered saline (PBS, pH 7.4), followed by $4 \%$ paraformaldehyde in PBS. The brains were cut $40 \mu \mathrm{m}$ thick by microtome. Every $12^{\text {th }}$ section was used for each of the following antigens.

For BrdU staining, DNA denaturation was performed by incubating section in $2 \mathrm{~N} \mathrm{HCl}$ for $30 \mathrm{~min}$ at $37^{\circ} \mathrm{C}$ (Kuhn et al., 1997). The sections were then incubated with $0.6 \% \mathrm{H}_{2} \mathrm{O}_{2}$ for 30 min to remove endogenous peroxidase activity. Anti-mouse BrdU (Chemicon MAB3424, Temecula, CA, USA) was used at a dilution of 1:2000 and incubated overnight at $4{ }^{\circ} \mathrm{C}$, and then sections were incubated with biotinylated horse anti-mouse secondary antibody (1:200, Vector Laboratories, Burlingame, CA, USA) at room temperature for $1 \mathrm{hr}$. Subsequently, avidin-biotin-peroxidase complex (ABC Elite Kit, Vector Laboratories) was added for $1 \mathrm{hr}$ at room temperature. The BrdU positive cells were visualized using DAB (nickel-enhanced diaminobenzidine).

For Ki67, DCX and cleaved caspase-3 staining, similar methods were used, omitting the DNA denaturing steps. Sections were heated in Citric acid (0.1M pH 6.0) for antigen retrieval, and tissues were incubated with either anti-rabbit Ki67 (1:400, Abcam, ab66155), DCX (1:1000, Abcam, ab18723) or cleaved caspase-3 (Asp 175) (1:1200, Cell signaling, \#9661) overnight at $4^{\circ} \mathrm{C}$.

Fluoro-Jade B (FJB) staining was employed in order to detect degenerative neurons (Schmued and Hopkins, 2000). For this procedure every $12^{\text {th }}$ section was mounted on Superfrost Plus ${ }^{\circledR}$ slides (Fisher Scientific), and dried overnight. Briefly, slides were immersed in 1\% NaOH in 80\% ethanol for $5 \mathrm{~min}$, followed by $2 \mathrm{~min}$ in $70 \%$ ethanol and 2 min in distilled water. After incubation in $0.06 \% \mathrm{KMnO} 4$ for $10 \mathrm{~min}$, the slides were rinsed for $2 \mathrm{~min}$ in distilled water. Then the slides were transferred to a solution containing $0.0002 \%$ FJB (Histo-Chem Inc., Jefferson, AR) and $0.1 \%$ acetic acid for $20 \mathrm{~min}$ in the dark. Slides were washed three times in distill water, dried and cover slipped with DPX mounting media.

Bioquant Nova Advanced Image Analysis (R\&M Biometric, Nashville, TN) was used for image capture and analysis (Crews et al., 2004) with an Olympus BX50 Microscope and Sony DXC-390 video camera linked to a computer. BrdU and Ki67 positive cells were quantified using profile counting in the granule cell layer (GCL) of the dorsal dentate gyrus with both sides of $3-5$ sections per rat (Bregma -2.30 to $-4.52 \mathrm{~mm}$ ). The number of the $\mathrm{BrdU}^{+}$and $\mathrm{Ki} 67^{+}$cells for every section was then averaged to represent each brain. For DCX-IR (immunoreactivity), the GCL of the dentate gyrus was outlined and staining density was measured in pixels for the outlined area $\left(\right.$ pixels $/ \mathrm{mm}^{2}$ ).

\subsection{Data analysis}

Statistical analyses were performed by using SPSS (IBM Corp, Armonk, NY). Multivariate Analysis of variance (ANOVAs, ANCOVAs) was used to determine the effects of chronic ethanol exposure on body weight, BECs and behaviors. Correlations between the behavioral measures and the measures of neurogenesis were made using Pearson correlations.

Significance was taken at $\mathrm{p}<0.05$.

\subsection{RESULTS}

\subsection{Body weight and BECs}

Figure 1 represents a time line of the ethanol exposure and withdrawal as well as the behavioral tests and the time of sacrifice for both experimental groups. As seen in figure 2, 
all rats gained weight over the course of the experiment. The 19 rats in the 72 day sacrifice group, who had neurogenesis data, grew from about $50 \mathrm{~g}$ at PD22 to about $360 \mathrm{~g}$ being $(365 \pm 27)$ and $(356 \pm 37) \mathrm{g}$ for control and ethanol at 7 weeks respectively. No significant overall differences in body weight were seen between the ethanol and control animals over the 7 week experiment in a group $\mathrm{X}$ time analysis (group effect: $\mathrm{F}=0.45, \mathrm{df}=1,17, \mathrm{p}<0.51$ ). The 23 rats in the 114 day sacrifice group who had BrdU data also grew, from about $50 \mathrm{~g}$ at PD22 to about $500 \mathrm{~g}$ being $525( \pm 27)$ and $557(485 \pm 39) \mathrm{g}$ (mean \pm S.D.) for control and ethanol at PD114 respectively. A significant difference in body weight between ethanol and control animals, sacrificed at 114 days, was found over the 13 week experiment in a group $\mathrm{X}$ time analysis (group effect: $\mathrm{F}=14.45, \mathrm{df}=1,21, \mathrm{p}<0.001$ ) with the controls being larger than the ethanol animals and larger than other controls run in similar experiments previously (Ehlers et al., 2011, 2013) (see figure 2). There were no significant differences in body weight between the ethanol exposed animals in the 72 day sacrifice group and the controls and ethanol exposed animals in the 114 day sacrifice group over the 5 weeks of ethanol exposure and two weeks following withdrawal $(\mathrm{F}=0.47, \mathrm{df}=1,30, \mathrm{p}<0.50)$, however the control animals in the 114 day sacrifice group were larger than the control and ethanol animals in the 72 day group and the ethanol animals in the 114 day group $(\mathrm{F}=18.4, \mathrm{df}=1,27$, $\mathrm{p}<0.0001)$. Therefore all subsequent analyses of the 114 day sacrifice group were co-varied for body weight.

Blood ethanol concentrations (BECs) were measured 8 times during the 5 week vapor exposure period and the values for each week are presented in figure 2. Mean blood ethanol concentrations $( \pm$ S.D. $)$ over the 5 week exposure period were $168.7( \pm 50) \mathrm{mg} / \mathrm{dL}$ for group 1 (72 day sacrifice) and $173.5( \pm 55.1) \mathrm{mg} / \mathrm{dL}$ for group 2 (114 day sacrifice). ANOVA of the mean BEC revealed that there was no significant overall difference between the two groups over the 5 week exposure period (group effect: $\mathrm{F}=0.05, \mathrm{df}=1,23, \mathrm{p}<0.825$ ).

\subsection{Locomotor behavior}

Locomotor behavior was assessed at two time points in the 114 day sacrifice group following ethanol withdrawal, at PD59, 24 hours after withdrawal and at 5 weeks following withdrawal from vapor exposure. An ANOVA that co-varied for body weight revealed that the ethanol animals were hypoactive at 24 hours following withdrawal (total beam breaks: ethanol $619.7 \pm 88$; control $=935 \pm 104)(\mathrm{F}=4.28, \mathrm{df}=1,22, \mathrm{p}=0.05)$ (data not shown). However, the ethanol exposed animals did not differ from controls in their locomotor activity levels at 5 weeks following withdrawal $(\mathrm{F}=1.25, \mathrm{df}=1,22, \mathrm{p}<0.28)$. Locomotor behavior has been reported previously in a larger group of animals that included some of the individuals in the 72 day sacrifice group (Ehlers et al., 2011).

\subsection{Behavior in the modified open field conflict test}

Behavior in the modified open field was assessed at PD105/106, 47 days after ethanol exposure ended in the 114 day sacrifice animals. Ethanol exposed animals spent significantly more time in the center of the open field $(F=20.8, d f=1,20, p<0.0001)$, closer distance to the food pellet $(\mathrm{F}=17.1 ; \mathrm{df}=1,20 ; \mathrm{p}<0.001)$, spent more time in contact with the food $(\mathrm{F}=23.0 ; \mathrm{df}=1,20 ; \mathrm{p}<0.0001)$ and ate significantly more food $(\mathrm{F}=23.62 ; \mathrm{df}=1,21$; $\mathrm{p}<0.0001$ ) than air exposed controls (see figure 3 ). These results in the open field conflict test suggest that the ethanol exposed animals may be displaying more disinhibitory behaviors or less "anxiety-like" behaviors as compared to control animals. Behavior in the open field conflict has been reported previously in a larger group of animals that included some of the individuals in the 72 day sacrifice group (Ehlers et al., 2011). 


\subsection{Behavior in the forced swim test}

Behavior in the forced swim test was assessed at PD111/112, 53 days after ethanol exposure ended. An ANOVA, that co-varied for body weight, revealed that air-exposed controls did not differ from the vapor-exposed animals on immobility and/or number of sinkings ( $\mathrm{n}=12$ ethanol, 10 control $)(\mathrm{F}=1.67, \mathrm{df}=1,21, \mathrm{p}<0.212)$ or defecations during the test session $(\mathrm{F}=0.86, \mathrm{df}=1,22 ; \mathrm{p}<0.36)$ (data not shown). Thus, the ethanol vapor-exposed animals at 52 days following withdrawal did not display a significant difference in behavioral signs indicative of "increased stress" or interpreted as an increased "depressive-like" state than controls in the forced swim test. Behavior in the forced swim test has been reported previously in a larger group of animals that included some of the individuals in the 72 day sacrifice group (Ehlers et al., 2011).

\subsection{Immunohistochemistry (IHC) for Doublecortin (DCX), Ki67, Cleaved capsase-3, fluoro- jade and BrdU}

Neurogenesis within hippocampal dentate gyrus was indexed using immunohistochemistry with quantification of immunoreactivity (+IR) for: (1) Ki67, a proliferation marker, (2) DCX, a marker of immature differentiating neurons, (3) cleaved caspase-3+IR, and Fluorojade, markers of dying cells and (4) BrdU+IR, to follow survival of progenitors that predominately differentiate into mature dentate gyrus neurons. Assessments were made in adulthood on days 71/72, 14 to 15 days following termination of 35 days of adolescent ethanol vapor exposure and on days 113/114, 55 to 56 days following termination of 36 days of ethanol vapor exposure. Ethanol exposure during adolescence resulted in alterations in NPC proliferation and survival. Ethanol vapor exposure was found to decrease Ki67+IR cells, a marker of proliferation. At PD72, 2 weeks following ethanol vapor treatment a $39.14 \pm 8.90 \%$ reduction in $\mathrm{Ki67}+\mathrm{IR}(\mathrm{F}=4.58 ; \mathrm{df}=1,15 ; \mathrm{p}<0.05)$ was seen and at PD113/114, 8 weeks following ethanol vapor exposure, a $30 \pm 7 \%$ decrease in Ki67+IR was seen that did not reach significance $(\mathrm{F}=3.39 ; \mathrm{df}=1,22 ; \mathrm{p}<0.08)$ (see figure 4$)$. A comparison of the values obtained for the 72 day sacrifice animals as compared to the 114 sacrifice animals using a $2 \times 2$ ANOVA (sacrifice group vs. ethanol exposure) revealed a significant reduction in Ki67 positive neurons in hippocampus with age $(\mathrm{F}=5.8 ; \mathrm{df}=1,35 ; \mathrm{p}<0.02)$ and ethanol $(\mathrm{F}=11.13 ; \mathrm{df}=1,35 ; \mathrm{p}<0.002)$ but with no significant interaction.

Neurogenesis is best assessed by DCX+IR since this protein is only expressed in immature neurons. Ethanol vapor exposed rats were found to have significantly less DCX+IR than control rats (figure 5). In animals sacrificed at 72 days, ethanol vapor treatment caused $42 \pm$ $7 \%$ reduction in $\mathrm{DCX}+\mathrm{IR}(\mathrm{F}=7.69 ; \mathrm{df}=1,17 ; \mathrm{p}<0.014)$, as compared to age-matched controls. Similarly, in the 114 day sacrifice animals, an ANOVA that was co-varied for body weight revealed a $47 \pm 5 \%$ reduction in $\mathrm{DCX}+\mathrm{IR}(\mathrm{F}=6.76$; $\mathrm{df}=1,22 ; \mathrm{p}<0.017)$. A comparison of the values obtained for the 72 day sacrifice animals as compared to the 114 sacrifice animals using a $2 \times 2$ ANOVA (sacrifice group vs. ethanol exposure) revealed a significant reduction in DCX+IR neurons with age $(\mathrm{F}=11.8 ; \mathrm{df}=1,40 ; \mathrm{p}<0.001)$ and ethanol $(\mathrm{F}=18.89$; $\mathrm{df}=1,40 ; \mathrm{p}<0.0001)$ but no significant interaction. These findings are consistent with earlier studies finding adolescent neurogenesis declines with increasing age (He and Crews, 2007).

Ethanol treated animals also had significantly increased cleaved caspase-3+IR, and FluoroJade, markers of cell death, within the dentate gyrus at PD72 (caspase-3+IR: F= 61.3, $\mathrm{df}=1,9, \mathrm{p}<0.0001$ ) (Fuoro-Jade: $\mathrm{F}=36.06, \mathrm{df}=1,9, \mathrm{p}<0.0001$, see figure 6) and at PD114: (caspase-3+IR: $\mathrm{F}=14.2, \mathrm{df}=1,19, \mathrm{p}<0.002$ (figure 4). A comparison of the values obtained for the 72 day sacrifice animals as compared to the 114 sacrifice animals for caspase-3+IR using a $2 \times 2$ ANOVA (sacrifice group vs. ethanol exposure) revealed a significant increase in cleaved caspase-3+IR with age $(\mathrm{F}=45.3 ; \mathrm{df}=1,30 ; \mathrm{p}<0.0001)$ and ethanol $(\mathrm{F}=81.2$; $\mathrm{df}=1,30 ; \mathrm{p}<0.0001)$ but no significant interaction. To assess survival of differentiating NPC, 
rats were treated with BrdU from PD61-65 and BrdU+IR cells were quantified at PD114, well after the 30 days needed for proliferating NPC to differentiate into mature dentate granule cells. A $31 \pm 5 \%$ reduction in BrdU+IR cells on PD114 in adolescent vapor treated rats was found (ANOVA co-varied for body weight: $F=5.21 ; \mathrm{df}=1,22 ; \mathrm{p}<0.034$ ) as compared to controls (figure 4). Thus, adolescent ethanol vapor treatment leads to a persistent decrease in proliferating NPC (Ki67), a decrease in NPC forming immature neurons (DCX), an increase in cell death (cleaved caspase-3, Fluoro-Jade) and a decrease in survival of differentiating progenitors (BrdU). Taken together these studies indicate that adolescent ethanol vapor treatment leads to a persistent loss of adult neurogenesis that is sustained for at least 8 weeks, during a time when age associated decreases in control neurogenesis are seen.

\subsection{Correlations of measures of neurogenesis to behavior}

The reductions seen in measures of neurogenesis in the ethanol vapor treated animals at PD72 and PD114 were also found to be correlated with measures of behavior. Specifically, hypoactivity at 24 hours following withdrawal was correlated with reduced counts of cells labeled with DCX $(\mathrm{r}=0.487 ; \mathrm{df}=1,17 ; \mathrm{p}<0.04)$ at 72 days and with reduced counts of cells labeled with DCX (r=0.542; df=1,20; $\mathrm{p}<0.009)$ and Ki67 (r=0.510; df=1,20; p<0.015) at 114 days (figure 7). Reductions in measures of neurogenesis were also significantly correlated with the increases in measures of disinhibitory behavior in the open field conflict test. Increased number of approaches to the food pellet was significantly correlated with reduced counts of cells labeled with DCX at 72 days $(r=-0.494 ; \mathrm{df}=1,17 ; \mathrm{p}<0.037)$, and shorter distance from the food pellet $(\mathrm{r}=0.714 ; \mathrm{df}=1,15 ; \mathrm{p}<0.001)$ at 114 days. Reduced cell counts of DCX were also correlated with more time spent in the center of the open field at 114 days $(\mathrm{r}=-0.496 ; \mathrm{df}=1,18 ; \mathrm{p}<0.026)$. Whereas at 72 days, but not at 114 days, reductions in both DCX labeled cells and Ki67 labeled cells were correlated with both the time spent in contact with the food [DCX ( $\mathrm{r}=-0.617 ; \mathrm{df}=1,17 ; \mathrm{p}<0.006), \mathrm{Ki67}(\mathrm{r}=-0.609 ; \mathrm{df}=1,15 ; \mathrm{p}<0.012)$ ] and the amount of food eaten [DCX $(r=-0.683 ; \mathrm{df}=1,17 ; \mathrm{p}<0.002), \operatorname{Ki67}(\mathrm{r}=-0.518$; $\mathrm{df}=1,15 ; \mathrm{p}<0.04)]$. No significant correlations were found between measures in the swim test and measures of neurogenesis.

\subsection{DISCUSSION}

In the present study, rats were exposed to ethanol vapors during the periadolescent period in order to examine ethanol's effects on neurogenesis and its relationship to behavior in adulthood. Blood ethanol concentrations over the 5 week exposure period were maintained at @ $170 \mathrm{mg} / \mathrm{dL}$, these blood ethanol levels are consistent with this protocol being a model of blood alcohol levels seen during adolescent binge drinking (Donovan, 2009). Two groups of animals were evaluated, group one was sacrificed at 72 days of age, 2 weeks following ethanol withdrawal, and group 2 was sacrificed at 114 days of age 8 weeks following ethanol withdrawal. Behaviors, BECs, and body weights in the 72 day sacrifice group have been reported previously (Ehlers et al., 2011). Ethanol vapor exposed rats, as compared to controls, in both groups, displayed hypoactivity in tests of locomotion and less anxiety-like and/or more "disinhibitory" behavior in the open field conflict. Quantitative analyses revealed a significant reduction in BrdU+ in the vapor exposed animals that were sacrificed at 114 days and reductions in doublecortin (DCX), a key index of neurogenesis, in the ethanol vapor exposed rats at both 72 and 114 days. These reductions were significantly correlated with less anxiety-like and/or more "disinhibitory" behavior in the open field conflict test. These studies demonstrate that behavioral measures of disinhibitory behavior correlated with decreases in neurogenesis are all significantly impacted by periadolescent ethanol exposure and withdrawal in Wistar rats. 
Alcohol vapor exposure can cause some changes in body weight during the exposure period (Slawecki et al., 2001). In the present study, the control animals in the second group (114 day sacrifice), were larger than the ethanol exposed rats and were also larger than the ethanol and control rats that were in the first group. Therefore, subsequent analyses were covaried for body weight. Following ethanol exposure and acute withdrawal, reductions in locomotor activity can be seen especially in animals exposed during adolescence (Slawecki and Roth, 2004; Ehlers et al., 2011). The decrease in locomotor behavior seen in the ethanol exposed animals in the 114 day sacrifice group and previously in the 72 day sacrifice group (Ehlers et al., 2011) is indicative of the fact that ethanol reached physiologically relevant levels able to induce signs of early withdrawal at 24 hours following termination of vapor exposure.

Several authors have suggested that the chronic effects of alcohol exposure may cause toxic effects on developing brain systems during adolescence that may then result in an increase in affective, impulsive and/or disinhibitory behaviors, which may in turn may facilitate further alcohol use (Crews and Boettiger, 2009; de Wit, 2009; White et al., 2011).

Adolescent ethanol exposure and withdrawal was also found to produce long lasting effects on measures derived from the open field test. In the standard open field, fewer entries into the center squares and/or less time spent in the center of the field have been suggested to be indicative of enhanced anxiety whereas; increased time spent in the center of the open field can be an index of disinhibitory behavior (Sarbadhikari et al., 1996; Blokland et al., 2002; Bowman et al., 2002; Yilmazer-Hanke et al., 2002). In the modified open field, an anxietylike profile is characterized by decreased approaches and time spent in the center of the field where the food is located, decreased time spent investigating and manipulating the food and decreases in the actual amount of food eaten whereas the opposite responses would indicate more disinhibitory behavior (Britton and Britton, 1981; Britton et al., 1982; Rex et al., 1998). A disinhibitory profile of behavior has been observed in the rats exposed to ethanol vapors during adolescence at 2 weeks following withdrawal (Ehlers et al., 2011). In the present study the ethanol exposed animals, sacrificed at 8 weeks following withdrawal, spent significantly more time in the center of the open field, more time near the food, spent more time in contact with the food and ate significantly more food than air exposed controls. Food contact time, in the modified open-field test, does not appear to be influenced by overall activity levels and/or increased level of arousal but may represent an increased "motivation" to enter the center of the open field, and/or less fear of open spaces or a combination of the two. Such behaviors may be a reflection of increased motivation to eat, perhaps driven by a greater hunger drive in ethanol exposed animals, resulting in more disinhibitory behavior. However, since all current analyses were co-varied for body weight, a more parsimonious explanation is that protracted neurobehavioral effects of adolescent ethanol exposure may include disinhibition. These data are also consistent with recent findings demonstrating that adult rats that "binged" on alcohol during adolescence exhibit increased exploration on the open arms of the elevated plus maze, a finding that the authors interpreted as possibly indicating either decreased anxiety or increased impulsivity (Gilpin et al., 2012). These findings suggest that adolescent alcohol exposure could contribute to long lasting increases in disinhibitory behaviors in adulthood.

In previous studies, we have found that ethanol vapor exposed animals may show indices of "depressive-like behavior" (e.g. more immobility/sinking) in the Forced swim test (FST) when compared with air-exposed controls after multiple weeks of withdrawal (Slawecki et al., 2004; Walker et al., 2010). Specifically, more immobility/sinking was seen following 2 weeks of withdrawal from 5 weeks of adolescent ethanol exposure between air- and vaporexposed animals sacrificed at 72 days (Ehlers et al., 2011). Those data are also consistent with clinical data showing that a proportion of individuals diagnosed with alcohol dependence develop depression in association with their drinking (Schuckit et al., 1997; 
Hasin and Grant, 2002). However, it has also been shown, in clinical studies, those major depressive symptoms, which are substance induced, generally only last for 2 to 4 weeks after abstinence is initiated (Brown and Schuckit, 1988). In the present study no differences in depressive-like behaviors were found in the forced swim test at 8 weeks following withdrawal from 5 weeks of adolescent ethanol vapor exposure. Therefore it appears that, similar to clinical findings, indices of increased depressive behavior can be seen following alcohol vapor exposure in early protracted withdrawal but the symptoms appear to abate further into protracted abstinence.

Adolescent alcohol exposure not only results in changes in affective, impulsive and or disinhibitory behaviors but also in concomitant measures of neuroplasticity. During maturation of the brain from adolescence to adults reduced plasticity is associated with a decline in synaptic pruning and maturation of neuronal circuits (see Spear, 2004). A high level of neurogenesis is found in the adolescent brain and is thought to be reflective of the high level of neuroplasticity that occurs during adolescence. Neurogenesis in both the forebrain and the hippocampus has been demonstrated to decrease dramatically from adolescence to adulthood (He and Crews, 2007). In the present study, indices of neurogenesis (DCX, BrdU) were also found to be significantly decreased when animals sacrificed at PD72 were compared to those sacrificed at 114 days. The reduction in neurogenesis corresponded with decreased proliferation of NPC (Ki67) and well as increased markers of cell death (cleaved caspase-3, Fluoro-Jade) consistent with decreases in the formation of NPC and increases in cell death among maturing NPC. These studies demonstrate that reductions in these plastic processes are occurring not only in adolescence but persist far into adulthood.

Molecular and cellular adaptations to drug exposure are also believed to lead to persistent changes in synaptic morphology and function that are extremely long-lived and may be analogous to the plastic processes that underlie learning and memory (Nestler, 2001; Ron and Jurd, 2005). In previous studies of acute and chronic ethanol "binge" treatment, both adult (Nixon and Crews, 2002) and adolescent rats (Crews et al., 2006) have been found to have reductions in hippocampal progenitor proliferation and neurogenesis. Reduced neurogenesis has also been demonstrated in adult rats which drank a liquid alcohol diet for two weeks that resulted in moderate blood alcohol levels (Anderson et al., 2012). However, hippocampal neurogenesis has been found to be more sensitive to acute low dose ethanol treatment in adolescents than in adults. Although neurogenesis is reduced by alcohol, following "binge" treatment, both adolescent (McClain et al., 2011) and adult rats (Nixon and Crews, 2004) have subsequent "bursts" of cell genesis. In adults "binge" alcohol treatment first inhibits neurogenesis, and then is followed by "bursts" of cell genesis that occur during the first week following the treatment, and finally return to control levels after a few weeks (Nixon and Crews, 2004). Further, models of alcohol dependence that include longer periods of adult rat vapor exposure lead to persistent deficits in forebrain neurogenesis, but hippocampal neurogenesis fully recovers (Hansson et al., 2010). Thus, previous studies in adults find ethanol inhibition of hippocampal neurogenesis is transient and recovers during abstinence from ethanol (Nixon and Crews, 2004; Hansson et al., 2010). To our knowledge this is the first study to investigate adult neurogenesis after chronic (more than 4 day) ethanol treatment of adolescent rats. In the present study, 5 weeks of ethanol adolescent vapor exposure resulted in persistent decreases in NPC proliferation and neurogenesis at both 2 weeks and at 8 weeks following withdrawal from ethanol. These data suggest that adolescent insults lead to persistent decreases in neurogenesis that are not found with adult ethanol exposure. Further, we report here increased cleaved caspase- 3 and Fluoro-Jade, markers of cell death in the hippocampus, are found long after the last day of ethanol exposure. These data contribute to an existing body of literature that find that alcohol is particularly toxic not only to the fetus but over the course of development (see 
Goodlett et al., 2005; Nixon et al., 2010). In the present study quantitative analyses of immunoreactivity revealed a significant reduction in Ki67+, doublecortin (DCX), and BrdU + cells in the vapor exposed animals. In addition, an increase in activated caspase-3+IR suggests increased cell death within the neurogenic dentate gyrus, consistent with an increase in progenitor cell death. Neurogenesis occurs due to unique factors within the hippocampus that create a "neurogeneic niche" that promotes NPC survival, proliferation and neurogenesis, and allows for formation and maturation of new neurons (Morrens et al., 2012). The findings presented here suggest that adolescent ethanol vapor exposure leads to persistent reductions in NPC proliferation and survival of hippocampal progenitors that contribute to a persistent loss of neurogenesis in adulthood that are likely the result of long term changes in the "neurogeneic niche".

Identifying the mechanisms by which ethanol modifies hippocampal structure and function and determining the resultant effects on behavior and cognition should give clues to how early alcohol exposure produces increased risk for the development of dependence.

Although a number of previous studies have made progress on elucidating the effects of ethanol on a number of aspects of neurogenesis, few studies have demonstrated that the effects are associated with any changes in behavior. In the present study reduction in measures of neurogenesis were significantly correlated with hypoactivity at 24 hours after withdrawal as well as less anxiety-like and/or more "disinhibitory" behavior in the open field conflict test at 2 and 8 weeks following termination of vapor exposure. Specifically, hypoactivity at 24 hours following withdrawal was correlated with reduced counts of cells labeled with DCX at 72 days and with reduced counts of cells labeled with DCX and Ki67 at 114 days.

Reductions in measures of neurogenesis were also significantly correlated with a number of measures of disinhibitory behavior in the open field conflict test. Increased time spent approaching or being near the food pellet was significantly correlated with reduced counts of cells labeled with DCX at 72 days and 114 days. Several authors have posited that acute and chronic effects of alcohol may cause toxic effects on developing brain systems that may result in an increase in affective, impulsive and or disinhibitory behaviors, which may in turn facilitate further alcohol use (Crews and Boettiger, 2009; de Wit, 2009; White et al., 2011). Our data support the hypothesis that ethanol exposure during adolescence may lead to indices of increased impulsive and/or disinhibitory behaviors but do not provide support for changes in affective behavior. Long term vapor exposure during adolescence and young adulthood has also been demonstrated to result in some increases in voluntary alcohol drinking (Criado and Ehlers, 2012). Further studies will be necessary to determine if changes in neurogenesis are directly correlated with measures of voluntary alcohol consumption.

It is known that hippocampal regions of the adolescent brain are highly sensitive to excitotoxic insult (Johnston, 1995). Our previous studies have demonstrated using diffusion tensor imaging (DTI), that volumetric measures of hippocampus are significantly impacted by age and time following periadolescent ethanol exposure (Ehlers et al., 2013).

Specifically, 5 weeks of ethanol vapor exposure, identical to what has been described in the present study, resulted in significant reductions in hippocampal size and non-significant decreases in corpus callosum, in Wistar rats sacrificed at 128 but not 72 days following withdrawal. These studies are in contrast to previous MRI data published in ethanol vapor treated adult rats where significant decreases in corpus callosum were observed but only non-significant significance decreases in hippocampus (Pfefferbaum et al. 2006). It has been suggested that reductions in neurogenesis may participate in the process that leads to reduced hippocampal size and neurodegeneration (Nixon et al., 2010; Winner et al., 2011) seen in human adolescents with a history of alcohol drinking (see DeBellis et al., 2000; 
Nagel et al., 2005; Medina et al., 2007). Although studies in humans are confounded by uncertainty regarding whether these findings represent a consequence of alcohol exposure or are a pre-existing condition associated with risk for alcohol use. In the present study reductions in indices of neurogenesis were observed at both 2 weeks and 8 weeks following withdrawal from 5 weeks of adolescent ethanol exposure. However, in our previous studies, DTI volumetric measures of hippocampal size were only found to be decreased at 10 weeks and not at 2 weeks following withdrawal from ethanol. Although the mechanisms of decreased hippocampal volume most likely include many factors, it is possible that the cumulative effect of a persistent loss of neurogenesis combined with cell death over a long period of time contribute to hippocampal volume loss that is only observed in the older animals. We found that alcohol associated reductions in the size of the hippocampus at 128 days, as imaged by DTI, were also correlated with reduced sensory gating and increases in disinhibitory behavior in the light/dark box (Ehlers et al., 2013). This suggests that these behavioral processes associated with hippocampal pathology are also persisting long after withdrawal from ethanol.

\subsection{CONCLUSIONS}

Thus our data support the hypothesis that adolescent ethanol exposure can have significant effects on brain and behavior in an animal model where control of ethanol exposure can help delineate environmental effects from genetic background. In the present study, rats were exposed to ethanol vapors during the periadolescent period in order to examine ethanol's effects on neurogenesis and its relationship to behavior in adulthood. Ethanol vapor exposed rats, as compared to controls, displayed hypoactivity in tests of locomotion and less anxietylike and/or more "disinhibitory" behavior in the open field conflict test. Quantitative analyses of immunoreactivity revealed a significant reduction in hippocampal NPC proliferation, neurogenesis and survival as well as increases in cell death that persists for weeks following vapor exposure. These reductions in markers of neurogenesis were significantly correlated with less anxiety-like and/or more "disinhibitory" behavior in the open field conflict test. These studies demonstrate that behavioral measures of disinhibitory behavior correlated with decreases in neurogenesis are all significantly impacted by periadolescent ethanol exposure and withdrawal in Wistar rats. Additional studies will be necessary to determine whether shorter intermittent periods of exposure produce similar effects, and to test whether such effects are persistent farther into adulthood.

\section{Acknowledgments}

This study was supported in part by the NADIA Initiative Project of the NIH National Institute on Alcoholism and Alcohol Abuse grants AA019969 (CLE) and AA020022, AA020023 and AA020024 (FTC) and the UNC Bowles Center for Alcohol Studies. The authors thank Jose Criado and Greta Berg for their assistance in data collection and Shirley Sanchez for editing the manuscript.

\section{Abbreviations}

$\begin{array}{ll}\text { a.m } & \text { ante meridiem } \\ \text { ANOVA } & \text { analysis of variance } \\ \text { BACs } & \text { blood alcohol concentrations } \\ \text { BECs } & \text { blood ethanol concentrations } \\ \text { BrdU+ } & \text { Bromodeoxyuridine } \\ \text { cm } & \text { centimeter }\end{array}$


DAB nickel-enhanced diaminobenzidine

DCX doublecortin

DG hippocampal dentate gyrus

FJB Fluoro-Jade B

FST Force swim test

g grams

GCL granule cell layer

hr hours

IHC immunohistochemical

IR immunoreactivity

$\mathbf{m g} / \mathbf{d l} \quad$ milligrams per deciliter

$\mathbf{m g} / \mathbf{k g} \quad$ grams per kilogram

mg\% milligrams percent

msec milliseconds

mm millimeters

NPC neural progenitor cells

NIH National Institutes of Health

p.m post meridiem

PBS phosphate buffered saline

PD postnatal day

SVZ forebrain subventricular zone

\section{References}

Altman J, Das GD. Autoradiographic and histological evidence of postnatal hippocampal neurogenesis in rats. J Comp Neurol. 1965; 124:319-335. [PubMed: 5861717]

Anderson ML, Nokia MS, Govindaraju KP, Shors TJ. Moderate drinking? Alcohol consumption significantly decreases neurogenesis in the adult hippocampus. Neuroscience. 2012; 224:202-209. [PubMed: 22906480]

Balu DT, Lucki I. Adult hippocampal neurogenesis: regulation, functional implications, and contribution to disease pathology. Neurosci Biobehav Rev. 2009; 33:232-252. [PubMed: 18786562]

Barha CK, Brummelte S, Lieblich SE, Galea LA. Chronic restraint stress in adolescence differentially influences hypothalamic-pituitary-adrenal axis function and adult hippocampal neurogenesis in male and female rats. Hippocampus. 2011; 21:1216-1227. [PubMed: 20665592]

Blokland A, Lieben C, Deutz NE. Anxiogenic and depressive-like effects, but no cognitive deficits, after repeated moderate tryptophan depletion in the rat. J Psychopharmacol. 2002; 16:39-49. [PubMed: 11949770]

Boldrini M, Underwood MD, Hen R, Rosoklija GB, Dwork AJ, John MJ, Arango V. Antidepressants increase neural progenitor cells in the human hippocampus. Neuropsychopharmacology. 2009; 34:2376-2389. [PubMed: 19606083]

Bowman RE, Ferguson D, Luine VN. Effects of chronic restraint stress and estradiol on open field activity, spatial memory, and monoaminergic neurotransmitters in ovariectomized rats. Neuroscience. 2002; 113:401-410. [PubMed: 12127097] 
Britton DR, Britton KT. A sensitive open field measure of anxiolytic drug activity. Pharmacol Biochem Behav. 1981; 15:577-582. [PubMed: 6117083]

Britton DR, Koob GF, Rivier J, Vale W. Intraventricular corticotropin-releasing factor enhances behavioral effects of novelty. Life Sci. 1982; 31:363-367. [PubMed: 6983018]

Brown SA, Schuckit MA. Changes in depression among abstinent alcoholics. J Stud Alcohol. 1988; 49:412-417. [PubMed: 3216643]

Clark DB, Thatcher DL, Tapert SF. Alcohol, psychological dysregulation, and adolescent brain development. Alcohol Clin Exp Res. 2008; 32:375-385. [PubMed: 18241320]

Crews FT, Nixon K, Wilkie ME. Exercise reverses ethanol inhibition of neural stem cell proliferation. Alcohol. 2004; 33:63-71. [PubMed: 15353174]

Crews FT, Mdzinarishvili A, Kim D, He J, Nixon K. Neurogenesis in adolescent brain is potently inhibited by ethanol. Neuroscience. 2006; 137:437-445. [PubMed: 16289890]

Crews FT, Boettiger CA. Impulsivity, frontal lobes and risk for addiction. Pharmacol Biochem Behav. 2009; 93:237-247. [PubMed: 19410598]

Criado JR, Ehlers CL. Effects of adolescent onset voluntary drinking followed by ethanol vapor exposure on subsequent ethanol consumption during protracted withdrawal in adult Wistar rats. Pharmacol Biochem Behav. 2012 [Epub ahead of print].

Czeh B, Lucassen PJ. What causes the hippocampal volume decrease in depression? Are neurogenesis, glial changes and apoptosis implicated? Eur Arch Psychiatry Clin Neurosci. 2007; 257:250-260. [PubMed: 17401728]

Dahl, RE.; Spear, LP. Adolescent brain development: Vulnerabilities and opportunities. New York, N.Y: The New York Academy of Sciences; 2004.

De Bellis MD, Clark DB, Beers SR, Soloff PH, Boring AM, Hall J, Kersh A, Keshavan MS. Hippocampal volume in adolescent-onset alcohol use disorders. Am J Psychiatry. 2000; 157:737744. [PubMed: 10784466]

de Wit H. Impulsivity as a determinant and consequence of drug use: a review of underlying processes. Addict Biol. 2009; 14:22-31. [PubMed: 18855805]

Doetsch F, Caille I, Lim DA, Garcia-Verdugo JM, varez-Buylla A. Subventricular zone astrocytes are neural stem cells in the adult mammalian brain. Cell. 1999; 97:703-716. [PubMed: 10380923]

Donovan JE. Estimated blood alcohol concentrations for child and adolescent drinking and their implications for screening instruments. Pediatrics. 2009; 123:e975-e981. [PubMed: 19482748]

Ehlers CL, Chaplin RI. Chronic ethanol exposure potentiates the locomotor-activating effects of corticotropin-releasing factor (CRF) in rats. Regul Pept. 1987; 19:345-353. [PubMed: 3501867]

Ehlers CL, Criado JR, Wills DN, Liu W, Crews FT. Periadolescent ethanol exposure reduces adult forebrain ChAT+IR neurons: correlation with behavioral pathology. Neuroscience. 2011; 199:333-345. [PubMed: 22033458]

Ehlers CL, Oguz I, Budin F, Wills DN, Crews FT. Periadolescent ethanol vapor exposure produces reductions in hippocampal volume that are correlated with deficits in prepulse inhibition of the startle. Alcohol Clin Exp Res. 2013 In Press.

Funk CK, O’Dell LE, Crawford EF, Koob GF. Corticotropin-releasing factor within the central nucleus of the amygdala mediates enhanced ethanol self-administration in withdrawn, ethanoldependent rats. J Neurosci. 2006; 26:11324-11332. [PubMed: 17079660]

Giedd JN, Rumsey JM, Castellanos FX, Rajapakse JC, Kaysen D, Vaituzis AC, Vauss YC, Hamburger SD, Rapoport JL. A quantitative MRI study of the corpus callosum in children and adolescents. Brain Res Dev Brain Res. 1996; 91:274-280.

Gilpin NW, Richardson HN, Cole M, Koob GF. Vapor inhalation of alcohol in rats. Curr Protoc Neurosci. 2008; Chapter 9(Unit)

Gilpin NW, Karanikas CA, Richardson HN. Adolescent binge drinking leads to changes in alcohol drinking, anxiety, and amygdalar corticotropin releasing factor cells in adulthood in male rats. PLoS One. 2012; 7:e31466. [PubMed: 22347484]

Goodlett CR, Horn KH, Zhou FC. Alcohol teratogenesis: mechanisms of damage and strategies for intervention. Exp Biol Med (Maywood ). 2005; 230:394-406. [PubMed: 15956769] 
Gould E, Woolf NJ, Butcher LL. Postnatal development of cholinergic neurons in the rat: I. Forebrain. Brain Res Bull. 1991; 27:767-789. [PubMed: 1664779]

Hanson ND, Owens MJ, Nemeroff CB. Depression, antidepressants, and neurogenesis: a critical reappraisal. Neuropsychopharmacology. 2011; 36:2589-2602. [PubMed: 21937982]

Hansson AC, Nixon K, Rimondini R, Damadzic R, Sommer WH, Eskay R, Crews FT, Heilig M. Long-term suppression of forebrain neurogenesis and loss of neuronal progenitor cells following prolonged alcohol dependence in rats. Int J Neuropsychopharmacol. 2010; 13:583-593. [PubMed: 20334723]

Hasin DS, Grant BF. Major depression in 6050 former drinkers: association with past alcohol dependence. Arch Gen Psychiatry. 2002; 59:794-800. [PubMed: 12215078]

He J, Nixon K, Shetty AK, Crews FT. Chronic alcohol exposure reduces hippocampal neurogenesis and dendritic growth of newborn neurons. Eur J Neurosci. 2005; 21:2711-2720. [PubMed: 15926919]

He J, Crews FT. Neurogenesis decreases during brain maturation from adolescence to adulthood. Pharmacol Biochem Behav. 2007; 86:327-333. [PubMed: 17169417]

Huttenlocher PR. Synapse elimination and plasticity in developing human cerebral cortex. Am J Ment Defic. 1984; 88:488-496. [PubMed: 6731486]

Johnston MV. Neurotransmitters and vulnerability of the developing brain. Brain Dev. 1995; 17:301306. [PubMed: 8579213]

Kuhn HG, Winkler J, Kempermann G, Thal LJ, Gage FH. Epidermal growth factor and fibroblast growth factor-2 have different effects on neural progenitors in the adult rat brain. J Neurosci. 1997; 17:5820-5829. [PubMed: 9221780]

Lidow MS, Goldman-Rakic PS, Rakic P. Synchronized overproduction of neurotransmitter receptors in diverse regions of the primate cerebral cortex. Proc Natl Acad Sci U S A. 1991; 88:1021810221. [PubMed: 1658799]

Markus EJ, Petit TL. Neocortical synaptogenesis, aging, and behavior: lifespan development in the motor-sensory system of the rat. Exp Neurol. 1987; 96:262-278. [PubMed: 3569455]

McClain JA, Hayes DM, Morris SA, Nixon K. Adolescent binge alcohol exposure alters hippocampal progenitor cell proliferation in rats: effects on cell cycle kinetics. J Comp Neurol. 2011; 519:26972710. [PubMed: 21484803]

Medina KL, Nagel BJ, Park A, McQueeny T, Tapert SF. Depressive symptoms in adolescents: associations with white matter volume and marijuana use. J Child Psychol Psychiatry. 2007; 48:592-600. [PubMed: 17537075]

Morrens J, Van Den BW, Kempermann G. Glial cells in adult neurogenesis. Glia. 2012; 60:159-174. [PubMed: 22076934]

Morris SA, Eaves DW, Smith AR, Nixon K. Alcohol inhibition of neurogenesis: a mechanism of hippocampal neurodegeneration in an adolescent alcohol abuse model. Hippocampus. 2010; 20:596-607. [PubMed: 19554644]

Nagel BJ, Schweinsburg AD, Phan V, Tapert SF. Reduced hippocampal volume among adolescents with alcohol use disorders without psychiatric comorbidity. Psychiatry Res. 2005; 139:181-190. [PubMed: 16054344]

Nestler EJ. Molecular basis of long-term plasticity underlying addiction. Nat Rev Neurosci. 2001; 2:119-128. [PubMed: 11252991]

Nixon K, Crews FT. Binge ethanol exposure decreases neurogenesis in adult rat hippocampus. J Neurochem. 2002; 83:1087-1093. [PubMed: 12437579]

Nixon K, Crews FT. Temporally specific burst in cell proliferation increases hippocampal neurogenesis in protracted abstinence from alcohol. J Neurosci. 2004; 24:9714-9722. [PubMed: 15509760]

Nixon K, Morris SA, Liput DJ, Kelso ML. Roles of neural stem cells and adult neurogenesis in adolescent alcohol use disorders. Alcohol. 2010; 44:39-56. [PubMed: 20113873]

Novati A, Hulshof HJ, Koolhaas JM, Lucassen PJ, Meerlo P. Chronic sleep restriction causes a decrease in hippocampal volume in adolescent rats, which is not explained by changes in glucocorticoid levels or neurogenesis. Neuroscience. 2011; 190:145-155. [PubMed: 21718758] 
O'Dell LE, Roberts AJ, Smith RT, Koob GF. Enhanced alcohol self-administration after intermittent versus continuous alcohol vapor exposure. Alcohol Clin Exp Res. 2004; 28:1676-1682. [PubMed: 15547454]

Perera TD, Park S, Nemirovskaya Y. Cognitive role of neurogenesis in depression and antidepressant treatment. Neuroscientist. 2008; 14:326-338. [PubMed: 18612087]

Pfefferbaum A, Mathalon DH, Sullivan EV, Rawles JM, Zipursky RB, Lim KO. A quantitative magnetic resonance imaging study of changes in brain morphology from infancy to late adulthood. Arch Neurol. 1994; 51:874-887. [PubMed: 8080387]

Pfefferbaum A, Adalsteinsson E, Sood R, Mayer D, Bell R, McBride W, Li TK, Sullivan EV. Longitudinal brain magnetic resonance imaging study of the alcohol-preferring rat. Part II: effects of voluntary chronic alcohol consumption. Alcohol Clin Exp Res. 2006; 30:1248-1261. [PubMed: 16792573]

Rex A, Voigt JP, Voits M, Fink H. Pharmacological evaluation of a modified open-field test sensitive to anxiolytic drugs. Pharmacol Biochem Behav. 1998; 59:677-683. [PubMed: 9512071]

Roberts AJ, Cole M, Koob GF. Intra-amygdala muscimol decreases operant ethanol selfadministration in dependent rats. Alcohol Clin Exp Res. 1996; 20:1289-1298. [PubMed: 8904984]

Roberts AJ, Heyser CJ, Cole M, Griffin P, Koob GF. Excessive ethanol drinking following a history of dependence: animal model of allostasis. Neuropsychopharmacology. 2000; 22:581-594. [PubMed: 10788758]

Rogers J, Wiener SG, Bloom FE. Long-term ethanol administration methods for rats: advantages of inhalation over intubation or liquid diets. Behav Neural Biol. 1979; 27:466-486. [PubMed: 575037]

Ron D, Jurd R. The "ups and downs" of signaling cascades in addiction. Sci STKE. 2005; 2005:re14. [PubMed: 16278489]

Sapolsky RM. Glucocorticoids and hippocampal atrophy in neuropsychiatric disorders. Arch Gen Psychiatry. 2000; 57:925-935. [PubMed: 11015810]

Sarbadhikari SN, Dey S, Ray AK. Chronic exercise alters EEG power spectra in an animal model of depression. Indian J Physiol Pharmacol. 1996; 40:47-57. [PubMed: 8864771]

Schmued LC, Hopkins KJ. Fluoro-Jade B: a high affinity fluorescent marker for the localization of neuronal degeneration. Brain Res. 2000; 874:123-130. [PubMed: 10960596]

Scholzen T, Gerdes J. The Ki-67 protein: from the known and the unknown. J Cell Physiol. 2000; 182:311-322. [PubMed: 10653597]

Schuckit MA, Tipp JE, Bergman M, Reich W, Hesselbrock VM, Smith TL. Comparison of induced and independent major depressive disorders in 2,945 alcoholics. Am J Psychiatry. 1997; 154:948957. [PubMed: 9210745]

Seeman P. Images in neuroscience. Brain development, X: pruning during development. Am J Psychiatry. 1999; 156:168. [PubMed: 9989550]

Slawecki CJ, Betancourt M, Cole M, Ehlers CL. Periadolescent alcohol exposure has lasting effects on adult neurophysiological function in rats. Brain Res Dev Brain Res. 2001; 128:63-72.

Slawecki CJ. Altered EEG responses to ethanol in adult rats exposed to ethanol during adolescence. Alcohol Clin Exp Res. 2002; 26:246-254. [PubMed: 11964565]

Slawecki CJ, Gilder A, Roth J, Ehlers CL. Increased anxiety-like behavior in adult rats exposed to nicotine as adolescents. Pharmacol Biochem Behav. 2003; 75:355-361. [PubMed: 12873627]

Slawecki CJ, Thorsell A, Ehlers CL. Long-term neurobehavioral effects of alcohol or nicotine exposure in adolescent animal models. Ann N Y Acad Sci. 2004; 1021:448-452. [PubMed: 15251927]

Slawecki CJ, Roth J. Comparison of the onset of hypoactivity and anxiety-like behavior during alcohol withdrawal in adolescent and adult rats. Alcohol Clin Exp Res. 2004; 28:598-607. [PubMed: 15100611]

Slawecki CJ, Jimenez-Vasquez P, Mathe AA, Ehlers CL. Effect of ethanol on brain neuropeptides in adolescent and adult rats. J Stud Alcohol. 2005; 66:46-52. [PubMed: 15830902]

Sowell ER, Thompson PM, Holmes CJ, Jernigan TL, Toga AW. In vivo evidence for post-adolescent brain maturation in frontal and striatal regions. Nat Neurosci. 1999b; 2:859-861. [PubMed: 10491602] 
Sowell ER, Thompson PM, Holmes CJ, Batth R, Jernigan TL, Toga AW. Localizing age-related changes in brain structure between childhood and adolescence using statistical parametric mapping. Neuroimage. 1999a; 9:587-597. [PubMed: 10334902]

Spear LP. The adolescent brain and age-related behavioral manifestations. Neurosci Biobehav Rev. 2000; 24:417-463. [PubMed: 10817843]

Spear LP. Adolescent brain development and animal models. Ann N Y Acad Sci. 2004; 1021:23-26. [PubMed: 15251870]

Squeglia LM, Jacobus J, Tapert SF. The influence of substance use on adolescent brain development. Clin EEG Neurosci. 2009; 40:31-38. [PubMed: 19278130]

Staff RT, Murray AD, Ahearn TS, Mustafa N, Fox HC, Whalley LJ. Childhood socioeconomic status and adult brain size: childhood socioeconomic status influences adult hippocampal size. Ann Neurol. 2012; 71:653-660. [PubMed: 22522480]

Taffe MA, Kotzebue RW, Crean RD, Crawford EF, Edwards S, Mandyam CD. Long-lasting reduction in hippocampal neurogenesis by alcohol consumption in adolescent nonhuman primates. Proc Natl Acad Sci U S A. 2010; 107:11104-11109. [PubMed: 20534463]

Trauth JA, Seidler FJ, Slotkin TA. An animal model of adolescent nicotine exposure: effects on gene expression and macromolecular constituents in rat brain regions. Brain Res. 2000; 867:29-39. [PubMed: 10837795]

van Eden, CG. The development of the rat prefrontal cortex: its size and development of connections with thalamus, spinal cord and other cortical areas. In: Uylings, HBM.; van Eden, CG.; DeBruin, JPC.; Corner, MA.; Feenstra, MGP., editors. Progress in brain research. Amsterdam: Elsevier Science; 1990. p. 169-183.

Walker BM, Drimmer DA, Walker JL, Liu T, Mathe AA, Ehlers CL. Effects of prolonged ethanol vapor exposure on forced swim behavior, and neuropeptide $\mathrm{Y}$ and corticotropin-releasing factor levels in rat brains. Alcohol. 2010; 44:487-493. [PubMed: 20705420]

White AM, Ghia AJ, Levin ED, Swartzwelder HS. Binge pattern ethanol exposure in adolescent and adult rats: differential impact on subsequent responsiveness to ethanol. Alcohol Clin Exp Res. 2000; 24:1251-1256. [PubMed: 10968665]

White HR, Marmorstein NR, Crews FT, Bates ME, Mun EY, Loeber R. Associations between heavy drinking and changes in impulsive behavior among adolescent boys. Alcohol Clin Exp Res. 2011; 35:295-303. [PubMed: 21073485]

Whitney NP, Eidem TM, Peng H, Huang Y, Zheng JC. Inflammation mediates varying effects in neurogenesis: relevance to the pathogenesis of brain injury and neurodegenerative disorders. $\mathrm{J}$ Neurochem. 2009; 108:1343-1359. [PubMed: 19154336]

Winner B, Kohl Z, Gage FH. Neurodegenerative disease and adult neurogenesis. Eur J Neurosci. 2011; 33:1139-1151. [PubMed: 21395858]

Yilmazer-Hanke DM, Faber-Zuschratter H, Linke R, Schwegler H. Contribution of amygdala neurons containing peptides and calcium-binding proteins to fear-potentiated startle and exploration-related anxiety in inbred Roman high- and low-avoidance rats. Eur J Neurosci. 2002; 15:1206-1218. [PubMed: 11982631]

Zahr NM, Bell RL, Ringham HN, Sullivan EV, Witzmann FA, Pfefferbaum A. Ethanol-induced changes in the expression of proteins related to neurotransmission and metabolism in different regions of the rat brain. Pharmacol Biochem Behav. 2011; 99:428-436. [PubMed: 21397625]

Zhao C, Deng W, Gage FH. Mechanisms and functional implications of adult neurogenesis. Cell. 2008; 132:645-660. [PubMed: 18295581] 


\section{Highlights}

Adolescence ethanol exposure produces disinhibitory behavior at 8 weeks withdrawal

Adolescence ethanol exposure reduces measures of progenitor proliferation

Adolescent ethanol exposure reduces progenitor survival and increases cell death

Reduced measures of neurogenesis were correlated with more disinhibitory behavior 
Study 1

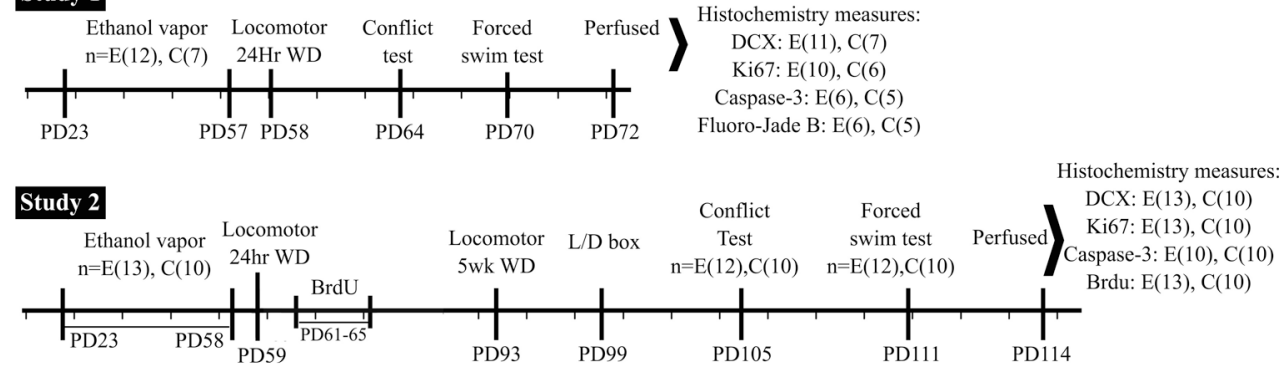

Figure 1.

Timelines representing two groups of animals used in this study. The first study (upper timeline) rats were sacrificed at PD72 and histochemical measures were collected subsequently, the second study (lower timeline) rats had behavioral measure from PD59 to PD111, BrdU was injected PD61-65, and neurochemical measures were evaluated after sacrifice at PD114. Shown with each timeline is the number (n) of subjects included in each analysis. 

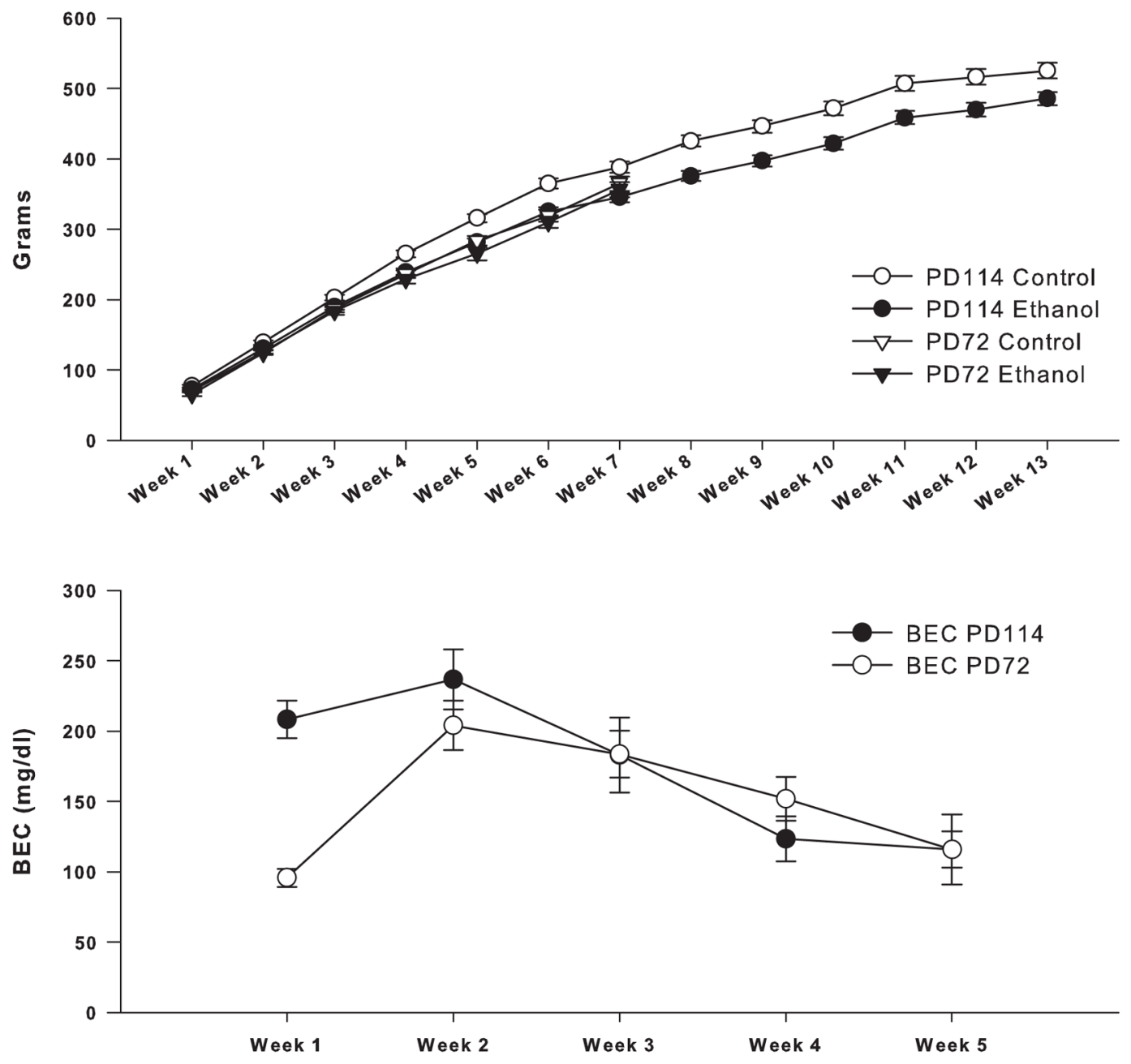

Figure 2.

Weekly means of body weights and BEC shown for ethanol and control rats sacrificed at 72 and 114 days of age. (Upper panel) For rats sacrificed at PD72, there were no significant differences in weight between ethanol $(n=12)$ and control $(n=7)$ animals over the 7 week experiment. Animals sacrificed at PD114 showed significant differences in body weight between ethanol $(n=13)$ and controls $(n=10)$ over the 13 weeks. However, the ethanol group sacrificed at PD114 was not significantly different from the control and ethanol animals sacrificed at PD72 over the 7 concurrent weeks. (Lower panel) Weekly means of blood ethanol concentrations (BECs) over the five week ethanol exposure. No significant difference was found between PD72 group $(n=12)$ and PD114 $(n=13)$ for the 5 week exposure period. Error Bars = S.E.M 

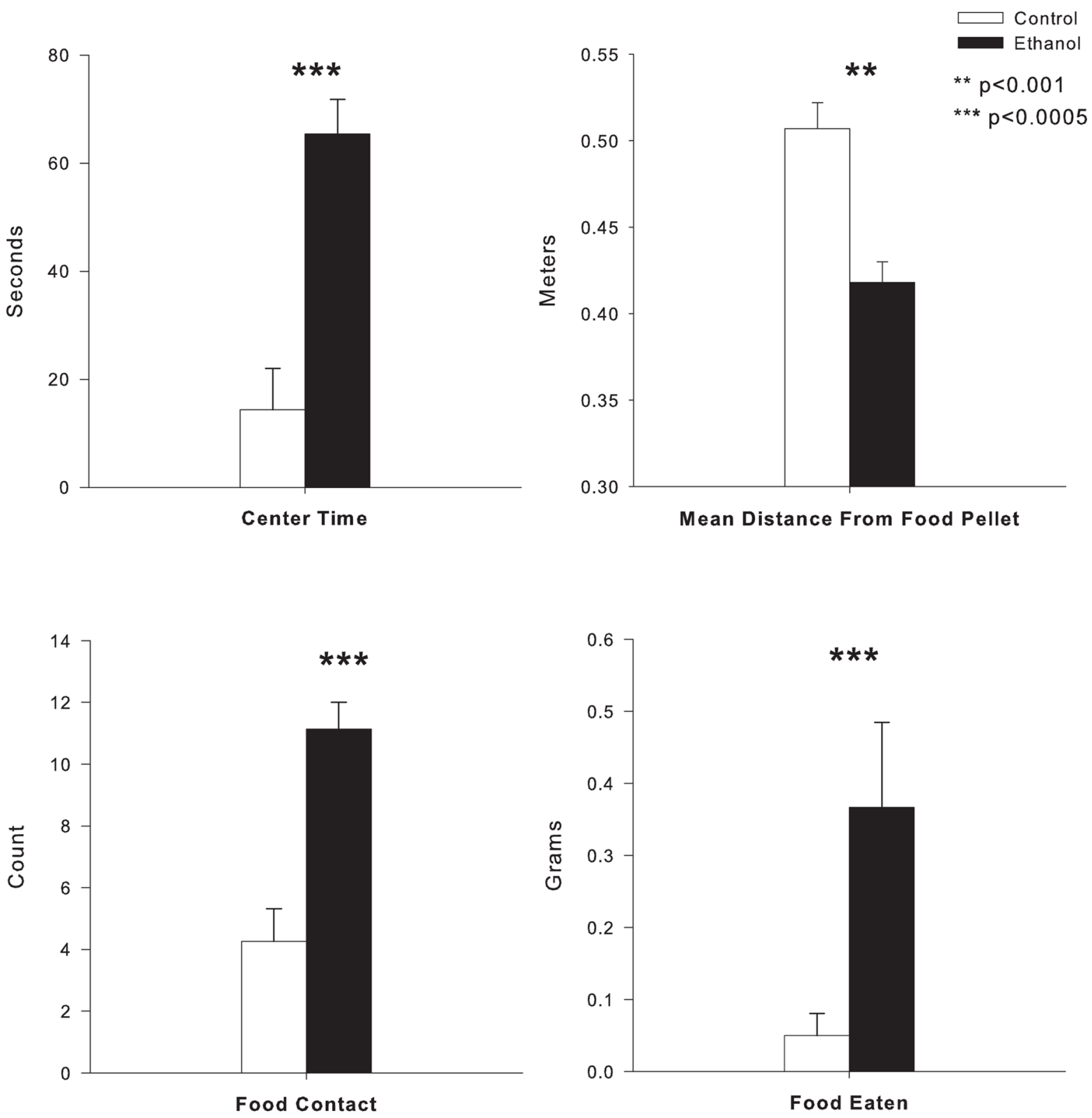

Figure 3.

Effects of adolescent ethanol exposure in the modified open field conflict test for rats sacrificed at PD114. Ethanol treated rats $(n=13)$ spend significantly more time in the lighted center, by multiple measures, than their controls $(n=10)$. (Top left) Total time spent in the center of the lit grid was higher in ethanol than controls, and mean distance from the food pellet (top right) was shorter in ethanol than controls as measured by automated video tracking software. (Bottom Left) Additionally, ethanol rats show significantly higher approaches to the food at the center, as well as higher total amount of food consumed (bottom right) compared to their controls. $* *$ indicates $\mathrm{p}=0.001$. $* * *$ indicates $\mathrm{p}<0.0005$. Error Bars = S.E.M 

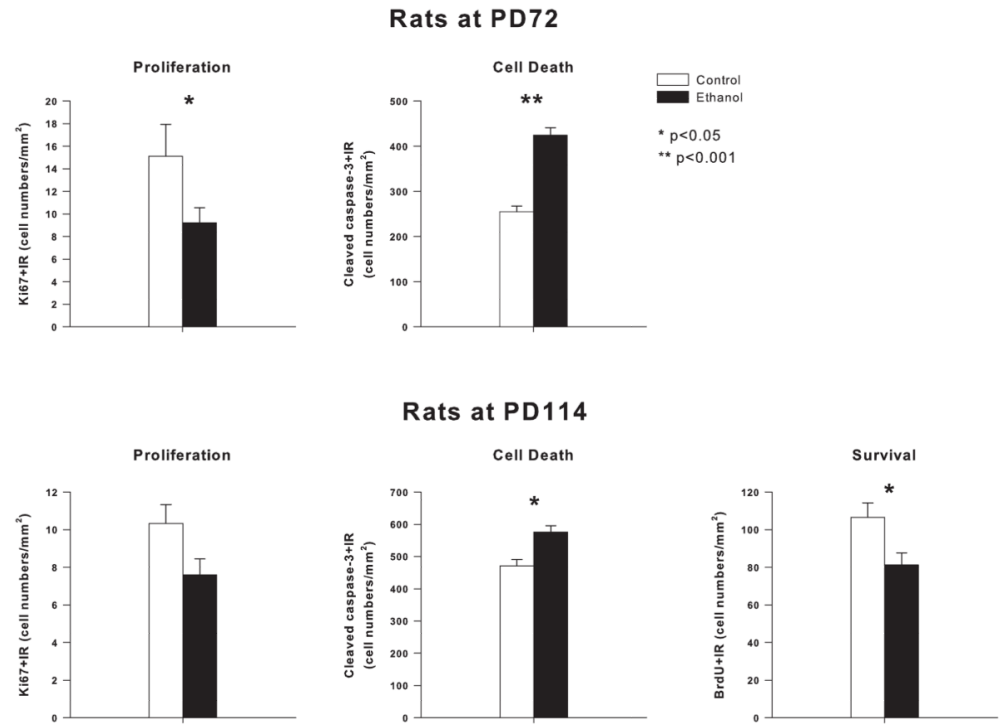

Figure 4.

Effects of adolescent ethanol vapor exposure on Ki67+IR (proliferation marker), BrdU+IR (30 day survival marker) and cleaved capsase- $3+$ IR (cell death marker) in the granular cell layer (GCL) of adult hippocampus for animals sacrificed at PD72 and PD114. (Top bar graphs) Rats sacrificed at PD72 following adolescent vapor treatment (ethanol) have decreased Ki67+IR cells and increased cleaved caspase-3+IR cells in hippocampal dentate gyrus (PD72, Ki67: $n=10$ ethanol, $n=6$ control; cleaved caspase-3+IR: $n=6$ ethanol, $n=5$ control). (Bottom bar graphs) Rats sacrificed at PD114 following adolescent vapor treatment (ethanol) have decreased Ki67+IR cells, increased cleaved caspase-3+IR cells and reduced BrdU+IR cell density in hippocampal dentate gyrus (PD114 Ki67: $\mathrm{n}=13$ ethanol, $\mathrm{n}=10$ control; cleaved caspase- 3 : $\mathrm{n}=10$ ethanol, $\mathrm{n}=10$ control; BrdU: $\mathrm{n}=13$ ethanol, $\mathrm{n}=10$ control). (Bottom right) All animals sacrificed at PD114 were given injections of BrdU between PD61-65, which was 72 hours following withdrawal of ethanol. *indicates $p \unlhd 0.05$; $* *$ indicates $p<0.001$. Error Bars $=$ S.E.M 

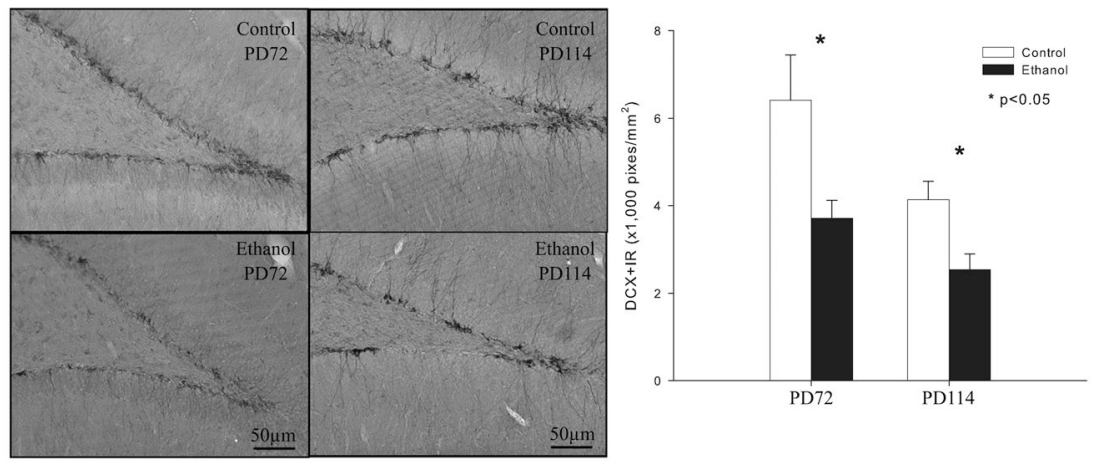

Figure 5.

Adolescent ethanol vapor exposure reduces neurogenesis. (Left) Images of doublecortinimmunoreactivity (DCX+IR) in the dentate gyrus granule cell layer of the hippocampus at the PD72 and PD114 in representative animals. PD72 control compared to PD114 control shows age related declines in neurogenesis. PD72 ethanol vapor treated rat shows reduced neurogenesis compared to PD72 control. PD114 ethanol vapor treated rat shows reduced neurogenesis compared to PD114 control. (Scale bar=50 $\mu \mathrm{m}$ ). Right bar graph: Quantitation of DCX+IR indicates ethanol vapor treatment reduces neurogenesis at both PD72 and PD114 (PD72 n=11 ethanol, n=7 control and PD114 n=13 ethanol, n=10 control). *indicates $p<0.05$, compared with the control groups at PD72 or PD114 separately. 

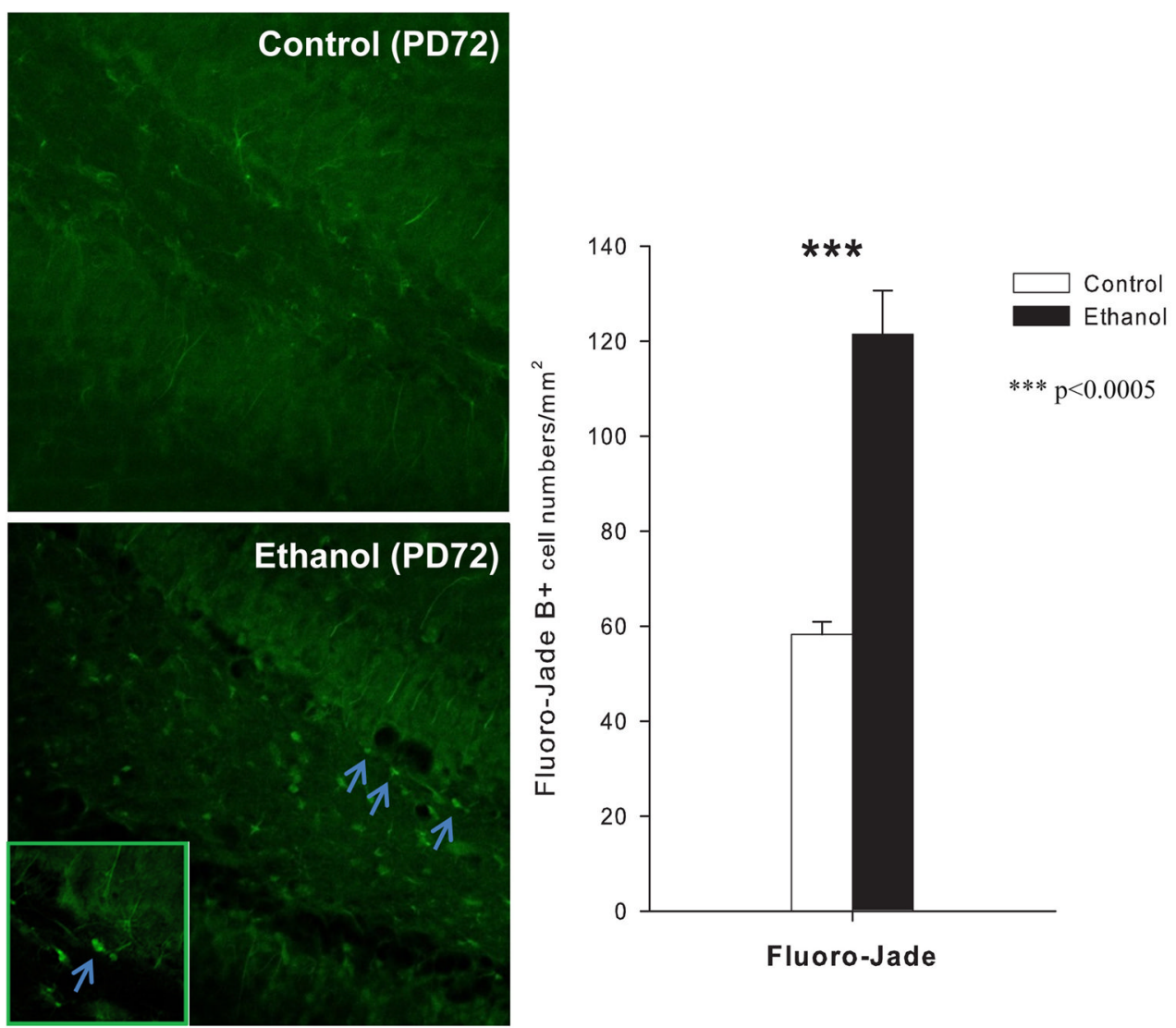

Figure 6.

Effects of adolescent ethanol vapor exposure on cell density of Fluoro-Jade B (FJB) in the granule cell layer of the hippocampus at PD72 ( $n=6$ ethanol, 5 control; Ethanol rats showed significant increases in the number of positive cells labeled with FJB compared to controls. $* * *$ indicates $\mathrm{p}<0.0005$. Error Bars $=$ S.E.M. Photomicrography of positive cells labeled with FJB is shown in left panel (original magnification $\times 40$; inside photo $\mathrm{x} 160$ ). 

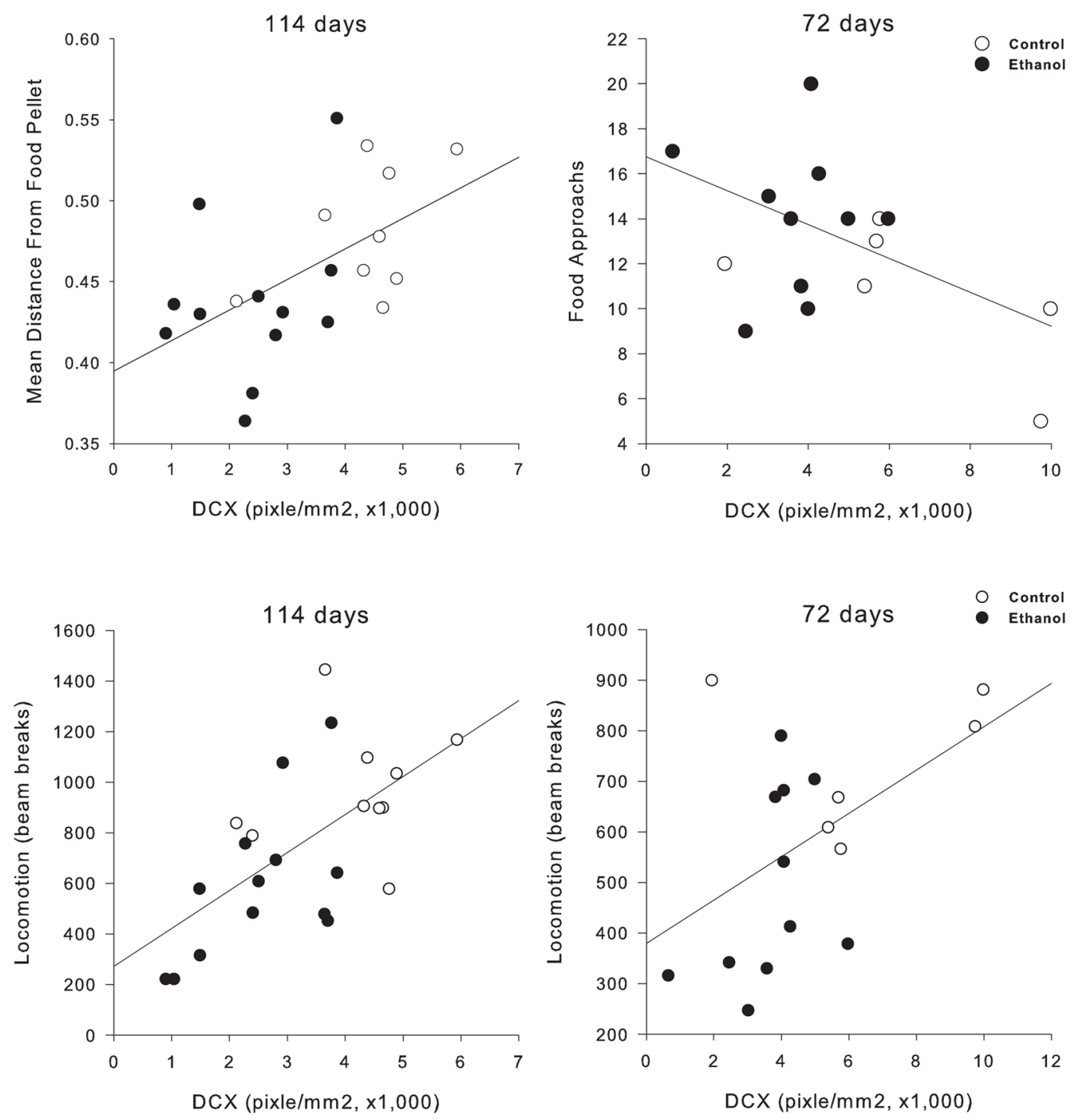

Figure 7.

Correlation of measures of neurogenesis and disinhibition in the open field conflict and locomotor behavior. (Upper panel) Correlations between DCX-IR measures of neurogenesis and the modified open field conflict for animals sacrificed at PD72 and PD114. For animals sacrificed at PD114, distance from the food pellet (shorter distance means more disinhibition) had a positive correlation with DCX-IR. This effect was similar to what was seen with animals sacrificed at PD72 where more food approaches are negatively correlated with DCX-IR. Both measures show that decreases in neurogenesis correlate with measures of disinhibition. (Lower panel) Correlations between DCX-IR measures of neurogenesis and locomotor behavior 24 hours withdrawal from alcohol for animals sacrificed at PD72 and PD114. Both groups of animals show a decrease in DCX-IR that correlates with a decrease in locomotor activity at 24 hours withdrawal from alcohol. Ethanol and control animals are graphed separately with a linear regression line plotted for all data points 